\title{
Drug Metabolism and Oxidative Stress: Cellular Mechanism and New Therapeutic Insights

\author{
Sharmistha Banerjee ${ }^{1}$, Jyotirmoy Ghosh ${ }^{2}$ and Parames C Sil ${ }^{1 *}$
}

${ }^{1}$ Division of Molecular Medicine, Bose Institute, P-1/12, CIT Scheme VII M, Kolkata 700054, India

${ }^{2}$ Chemistry Department, Banwarilal Bhalotia College Asansol, Ushagram, Asansol-713303, West Bengal, India

\begin{abstract}
Oxidative stress, generated during drug metabolism, acts as a source of origin and progression of many dreadful diseases. Reactive metabolites formed during this process cause oxidative stress and can impair the function of drugmetabolizing enzymes leading to toxicity. It is, therefore, important to investigate the mechanism of drug-induced toxicity and to find a remedy so that cellular toxicity can be minimized. This review highlights the mechanism of reactive oxygen species generation during cytochrome P450 mediated metabolism of various drugs and endogenous molecules, cytochrome mediated metabolism of arachidonic acid and the role of its metabolite, 20-Hydroxy-5,8,11,14eicosatetraenoic acid in cardiovascular diseases. This review aims to provide updated knowledge on the mechanism of reactive oxygen species generation during drug metabolism, association of drug metabolizing enzyme in diseases and the role of antioxidant therapy that helps to minimize cellular toxicity. The most significant challenges in drug discovery are the unpredictable nature of drug toxicity due to the oxidative stress in drug metabolism. These difficulties can be overcome by inhibiting toxic metabolites formation or by the modification of the structure of the original compounds for the amelioration of toxicity of the toxic metabolites. Another aspect of reducing drug toxicity is the inhibition of the drug metabolizing enzymes.
\end{abstract}

Keywords: Acetaminophen; Aminochrome; Doxorubicin; L-DOPA; Oxidative Stress; Quinone

Abbreviations: APAP: Acetaminophen; Ahr: Aryl Hydrocarbon Receptor; CYP: Cytochrome; DMA: Desmethylarzoxifene; GST: Glutathione-S-Transferase; 20 HETE: 20-Hydroxy-5,8,11,14Eicosatetraenoic Acid; 2-OHE: 2-Hydroxyestrogen; L-DOPA: L-Dihydroxyphenylalanine; MPTP: 1-Methyl-4-Phenyl-1,2,3,6Tetrahydro Pyridine; NRF2: NF-E2-Related Factor 2; NAPQI: N-Acetyl-P-Benzoquinone Imine; 2,3-QE: 2,3-Quinone Estrogen; 3.4-QE: 3,4-Quinone Estrogen; ROS: Reactive Oxygen Species; SERM: Selective Estrogen Receptor Modulators; SNP: Single Nucleotide Polymorphism.

\section{Introduction}

Reactive Oxygen Species (ROS), are formed as a byproduct of normal metabolism. These molecules play an important role in cellsignaling pathways and likely to act as key players in many diseases and homeostasis. Species include oxygen radicals and reactive non-radicals. Apart from normal physiological roles, excess ROS formation can also occur during stress such as toxicant exposure, radiation damage, and disease that subsequently produces oxidative stress [1]. This oxidative stress plays an important role in drug metabolism. Most of the drugs administered to patients are lipophilic in nature [2] and can enter into the cell easily through plasma membrane. However, to reach the target site for proper adsorption, distribution, and excretion, these drugs must be converted to hydrophilic molecules. The conversion of these nonpolar compounds into polar compounds is termed as drug metabolism. Drug and other xenobiotic metabolism occur through three phases, namely, phase I, phase II and phase III. The major enzyme that play a pivotal role in phase I is Cytochrome P450s (CYP families) [3]. CYP contains heme moieties and helps to oxidize lipophilic drugs for their conversion to the hydrophilic molecule. CYP is a part of microsomal monooxygenase system present in the endoplasmic reticulum. Usually, the poor coupling of the P450 catalytic cycle results in the continuous production of ROS which contributes to the oxidative stress. This stress has profound effect on signaling pathways and other cellular functions
[4,5]. Phase II of drug metabolism mainly involves glucuronidation catalyzed by UDP glucuronosyltransferase (UGT). In this process, glucuronic acid binds to a substrate having suitable functional group via covalent linkage. Detoxification of xenobiotics also involves the activity of glutathione-S-transferase and $\mathrm{NAD}(\mathrm{P}) \mathrm{H}$ : quinone oxidoreductases NQO1 and NQO2 to counteract oxidative stress during drug metabolism [2,6]. Phase III involves the participation of various transporters involved in drug metabolism. Since ROS is produced mainly in phase I of drug metabolism, so phase III is not that much important in this context.

Biotransformation of the drug is a complicated process consisting of several steps that lead to the production of ROS. Living beings have evolved with the ability to maintain homeostasis under normal physiological conditions. There exists a fine balance between production, sequestration and neutralization of ROS $[7,8]$. Oxidative stress occurs when the balance between pro and the antioxidant system gets disrupted. Most of the drugs and xenobiotics generate reactive quinone metabolites in the intermediate stage of their metabolism [6]. This ultimately results in the formation radicals and ortho quinone that reacts with nitrogen bases of DNA forming adducts [9]. These DNA adducts hinder DNA replication, alters epigenetic phenomena (like promoter methylation), and leads to accumulation of mutation and eventually cancer [10]. ROS, generated during biotransformation, can also help cytochrome P450 inhibition [11] and leads to cellular

*Corresponding author: Parames C Sil, Division of Molecular Medicine, Bose Institute, Kolkata, India, Tel: 9133-25693243; Fax: 9133-2355-3886; Email: parames@jcbose.ac.in

Received: January 20, 2016; Accepted: March 10, 2016; Published March 14 2016

Citation: Banerjee S, Ghosh J, Sil PC (2016) Drug Metabolism and Oxidative Stress: Cellular Mechanism and New Therapeutic Insights. Biochem Anal Biochem 5: 255. doi:10.4172/2161-1009.1000255

Copyright: (c) 2016 Banerjee S, et al. This is an open-access article distributed under the terms of the Creative Commons Attribution License, which permits unrestricted use, distribution, and reproduction in any medium, provided the original author and source are credited. 
stress and finally cell death. This review intends to provide updated knowledge on the mechanism of ROS generation during metabolism of various drugs, an endogenous defence mechanism to combat oxidative stress, association of drug metabolizing enzyme in diseases and antioxidant therapy.

\section{Reactive Oxygen Species Generation During Drug Metabolism}

Cytochrome P450 is involved in Reactive Oxygen Species (ROS) generation during phase I of drug metabolism. Substrate binding to CYP450 occurs via the combination of one molecule of oxygen to the enzyme leading to the formation of an oxy complex. The oxy complex thus formed is again reduced to peroxy complex that accepts two protons and produce water through intermediate reactions. Since ROS is generated during the intermediate stages of CYP-mediated biotransformation of drugs, their continuous production results in NADPH consumption by the CYP molecules [4]. Although it was mentioned earlier that ROS is generated during the reaction of CYP P450 with its substrate, the electron-transfer chain of microsome continues to oxidize NADPH and produce ROS even in the absence of any substrate [12]. This excessive ROS generation leads to repression of CYP gene expression (specifically CYP1A1 gene expression) is through the inactivation of the transcription factor, nuclear factor 1 [11] (Figure 1). Enzymes like lipooxygenase, cyclooxygenase and xanthine oxidase can also contribute to ROS production.

ROS generated during biotransformation of drugs consists of hydrogen peroxide, hydroxyl and superoxide radical. The hydroxyl radical is very reactive and can modify nitrogenous bases of DNA leading to DNA strand breakage. These ROS particularly superoxide radical gets protonated to form perhydroxyl radical. This radical plays a significant role in lipid peroxidation and membrane destabilization. These reactive species also reacts with nitric oxide (NO) forming peroxynitrite ion (ONOO) and exerting deleterious effect on DNA, protein and lipid molecule [8]. Peroxisome is also a source of hydrogen peroxide but catalase present in this organelle decomposes it into water and oxygen creating a fine balance at physiological condition.

\section{Oxidative Stress Generated by Drug Metabolites}

Most of the drugs and xenobiotics, to which human beings are exposed, generate quinone metabolites. Quinones are involved in electron transport. Quinone-quinol cycle leads to oxidative stress leading to devastating effect. Many drugs are converted to quinone metabolites during biotransformation. These quinone metabolites are reactive molecular species which forms adducts with macromolecules, anti-oxidant molecules like GSH and deplete the pool of antioxidant molecule like GSH thereby generating more ROS. Excessive ROS generation and sequestration of endogeneous antioxidant species lead to oxidative stress. Prolonged persistence of cellular stress causes sustained activation of stress responsive MAPKs ultimately manifesting into cell death (Figure 2).

\section{Acetaminophen}

Acetaminophen is a widely used as analgesic and antipyretic drug. This drug exerts pharmacological action through inhibition of cyclooxygenase 3 in the central nervous system and prostaglandin $\mathrm{E}_{2}$ It has been established that both the liver and extrahepatic tissues are primarily affected because of toxicity of Acetaminophen (APAP). In adults, very little amount $(\sim 1 \%)$ of the therapeutic dosing has been reported to be excreted in the urine; most of it (approximately
$63 \%)$ is metabolized via glucuronidation and the rest $(\sim 34 \%)$ by sulfation. Primarily, water-soluble metabolites are formed in these phase II reactions in the liver and are easily excreted via the kidney. Less than $5 \%$ of APAP, at the therapeutic doses, is oxidised to the reactive intermediate, electrophilic N-Acetyl-P-Benzoquinone Imine (NAPQI), by the microsomal P-450 enzyme system which, in turn, gets reduced by glutathione and subsequently excreted as a relatively benign compound, mercapturic acid. However, in the presence of excess APAP (beyond the therapeutic doses), stores of sulfate and glutathione are depleted, more of the APAP is alternatively routed to the CYP-450 mixed function oxidase system and more reactive intermediates (NAPQI) is generated. In other words, more severe glutathione depletion as well as massive production of metabolites occurs in this scenario. These free electrophilic intermediates form adduct with sulfhydryl and glutathione moieties on cellular proteins as a result of which cellular homeostasis is disrupted and ultimately initiates cell death. This has been reported for both the liver and kidney tissues in animal models [13].

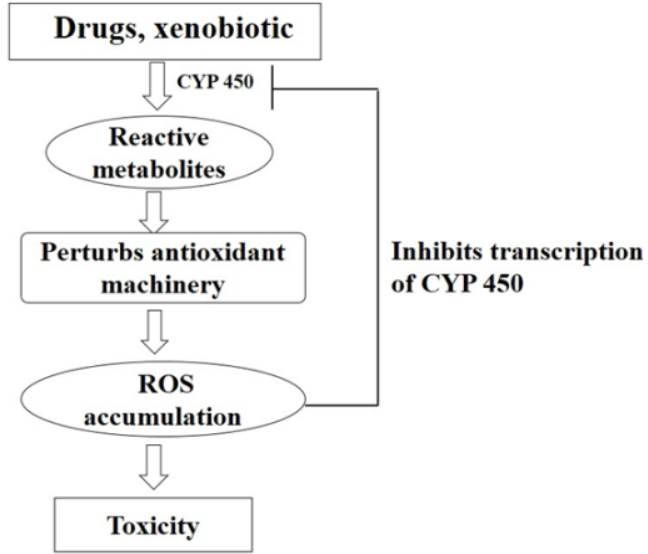

Figure 1: Flow chart depicting CYP mediated ROS generation and transcriptional repression of CYP.

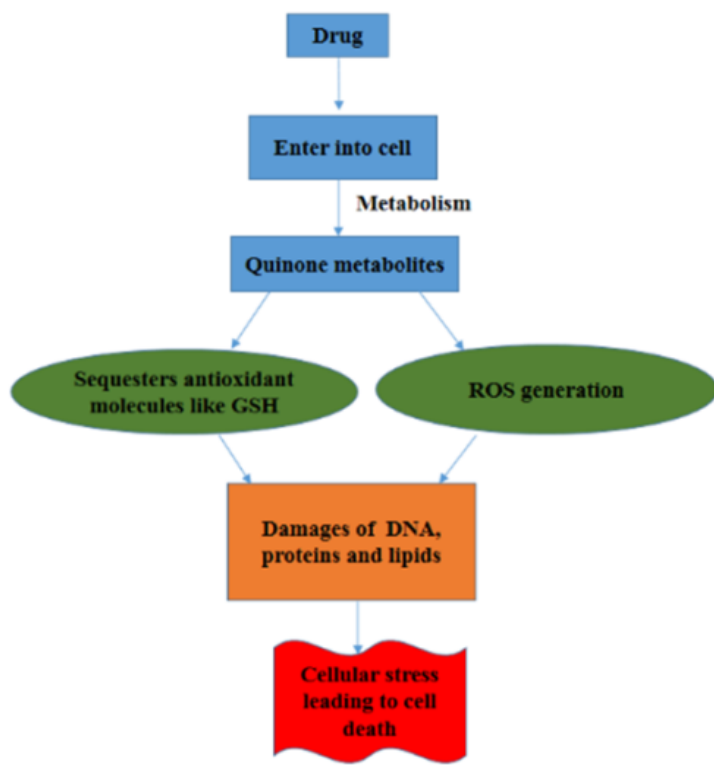

Figure 2: Flowchart depicting mechanism of drug metabolism induced cellular stress. 
Recent investigations clearly demonstrated the complex interplay between the pathways of toxin metabolism, intracellular signaling and the host inflammatory response. Among the various signaling molecules involved in the acetaminophen-induced hepatic damage, the signal transduction pathway of MAP kinase family proteins, JNK, is reported to be stimulated by both extracellular and intracellular stimuli including Reactive Oxygen Species (ROS), UV radiation and pro-inflammatory cytokines. This unique molecule can control many basic mammalian physiological processes including phosphorylation of specific subunits (c-Jun, JunB, JunD and ATF 2) of the activating protein 1 (AP-1) transcription factor. Besides, it can also activate the genes which regulate various types of functions including cell proliferation, survival and death [14] (Figure 3).

Micro RNA also plays a major role in APAP-induced hepatotoxicity. Micro RNA-122 is reported to be a novel biomarker of APAP-induced hepatotoxicity in adults. Search for potential micro RNA biomarkers of APAP-induced hepatotoxicity in children was also carried out. Global level of serum and urine micro RNAs were examined in three groups of children: 1) healthy children, 2) Hospitalized children who were receiving therapeutic doses of APAP, 3) hospitalized children receiving overdose of APAP. 147 miRNAs were detected in APAP overdose group. Out of 147,8 miRNAs were significantly increased in serum (miR-122, -375, -423-5p, -30d-5p, -125b-5p, -4732-5p, -204$5 p$, and $-574-3 p$ ) with respect to other 2 groups. Urine samples from the patients showed elevation in 4 miRNAs (miR-375, -940, -9-3p and -302a). Correlation of peak APAP-protein adduct level (indicator of NAPQI mediated oxidative stress $)$ with serum miR-122 $(\mathrm{R}=0.94 ; \mathrm{p}=$ $0.01)$ was observed followed by miR-375 $(\mathrm{R}=0.70 ; \mathrm{p}=0.05)$ [15].-

\section{Selective Estrogen Receptor Modulators (SERM)}

ManySERMare converted to quinone methides during bioactivation that accounts for cellular toxicity. Tamoxifen, a well-known anticancer agent, undergoes hydroxylation to 4-Hydroxytamoxifen catalyzed by CYP2D6. This 4-Hydroxytamoxifen gets oxidized via P450 mediated oxidation to para-quinone methide that forms stable adducts with nitrogen bases of DNA [16]. SERM, raloxifene, Desmethylarzoxifene (DMA) and bazedoxifene inhibit chemical carcinogenesis. Raloxifene and DMA up-regulate sulfotransferase (SULT 1E1) and glucuronidase

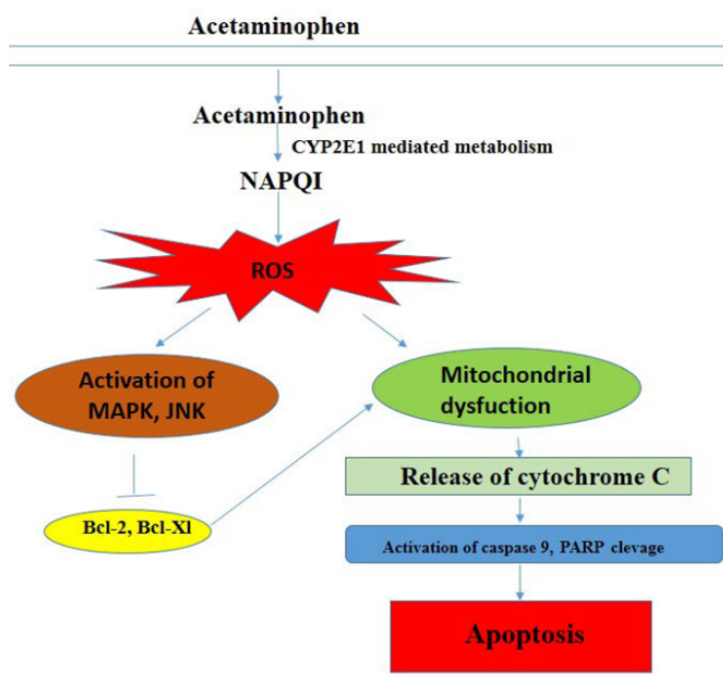

Figure 3: Mechanism of generation of ROS and cellular toxicity by acetaminophen.
(UGT 1A1). Up-regulation of phase II enzymes involved in drug metabolism helps in detoxification of catechol estrogen metabolites ultimately leading to attenuation of ROS formation. This reduced ROS formation inhibits malignant transformation caused by a subset of SERMs [17]. Estrogen is a hormone and is used in hormone replacement therapy (HRT) to improve menopause disorder. Its metabolism plays a crucial role in inducing oxidative stress and cellular toxicity. Estrogen gets converted to 2-Hydroxyestrogen (2-OHE) and 4-Hydroxyestrogen (4-OHE) during metabolism. 2-OHE gets converted to 2,3 Semiquinone Estrogen that gets converted to 2,3-Quinone Estrogen (2,3-QE). 4-OHE gets converted to 3, 4-Semiquinone Estrogen that ultimately enters into redox cycle to generate 3, 4-Quinone Estrogen (3.4-QE). These two metabolites (2, 3-QE and 3, 4-QE) cause cellular toxicity and build a smooth road towards carcinogenesis by activating NRF2 and inducing Heme Oxygenase 1 (HO-1) expression [18].

\section{Antipsychotic Drug}

Clozapine is a frequently prescribed antipsychotic drug that causes a severe adverse reaction. Oxidative bioactivation of this drug by CYP450 families generates reactive nitrite ion, clozapine- $\mathrm{N}$-oxide. These reactive intermediates generated during metabolism, cause ROS formation and impose oxidative stress. CYPs, particularly CYP3A4 and CYP2D6 (having highest specific activity), convert clozapine to GSH reactive nitrenium ions. Between these two, CYP3A4 is more important because it is highly expressed in the liver as compared to CYP2D6. Studies on bioactivation of clozapine from liver microsomes of one hundred individual samples showed eight-fold variability in the activity of CYP3A4. Inter individual differences and drug interactions at CYP3A4 level determine the exposure of the hepatic tissue to reactive metabolites [19]. Recently, use of clozapine has been restricted because of its life-threatening risk of inducing neutropenia and agranulocytosis [20]. So efforts have been made to modify the structure of clozapine to minimize the nitrenium ion formation. Quetiapine is one such clozapine inspired drug used in the treatment of schizophrenia [21,22]. This antipsychotic drug undergoes bioactivation by cytochromeP450 D26 and gets converted to 7-hydroxyquitiapiene. This 7-hydroxyquitiapine is further oxidized by myeloperoxidase to generate reactive quinone imine that accounts for neurotoxicity [20].

Chlorpromazine is a member of the largest class of antipsychotic drug. This drug is known to cause hepatotoxicity in some patients. This molecule is converted to toxic quinone imine metabolite by CYP2D1 and CYP1A2. It also undergoes peroxidase catalyzed oxidation to generate toxic radicals that account for hepatic pathophysiology [23].

\section{Relation of Toxicity with Chemical Structure}

Phenothiazine derivatives (PTZs) are used for the treatment of schizophrenia and anxiety [24]. These derivatives are a class of heterocyclic compounds having a tricyclic phenothiazine nucleus (PHT) with the central ring containing sulfur and nitrogen atoms. Phenothiazine derivatives (PTZs) are substituted at position 2 and 10; nature of the ligand at position 10 determines the pharmacological antipsychotic activity and the presence of electron withdrawing groups at position 2 increases therapeutic efficiency of these drugs. PTZs can be classified as aliphatic, piperazine, or piperidine derivatives based on 10-position substituents [25]. These drugs exert a toxic effect on liver including acute intrahepatic cholestasis [25] and hepatitis [26]. De Faria et al. has investigated the structural features of drugs (chlorpromazine, CPZ; fluphenazine, FP; thioridazine, TR; trifluoperazine, TFP; and triflupromazine, TFPZ), responsible for hepatotoxicity of these PTZs [24]. De Farria et al. demonstrated that the cytotoxic effect of IMP was 
very low compared to that of CPZ. The chemical structure of both the drugs are quite similar to each other except that the sulphur atom of the PHT ring is substituted by two methylene groups, leading to the decrease in reactivity of the sulphur atom and resonance of the tricyclic structure [24]. The toxic effect of PTZs also depends on the side chains of PTZs. Derivatives of PTZs containing piperazine or piperidine amine groups linked to a small chain from the phenothiazinic nitrogen accounts for toxicity. De Faria et al. demonstrated that piperidine derivative containing TR was the most cytotoxic in HTC cells among all the drugs used in the study. Piperazine and aliphatic derivatives follow piperidine, group. The cytotoxicity increases in the following order TR $>$ TFP $>$ FP $>$ TFPZ $>$ CPZ. The order of potencies based on substituents at $\mathrm{C} 2$ is $\mathrm{SCH}_{3}>\mathrm{CF}_{3}>\mathrm{Cl}$, and that of at $\mathrm{N} 10$ is piperidine $>$ piperazine $>$ aliphatic. The cytotoxic effect of these drugs varies from one cell to another. In leukemia cell lines, PTZ with $\mathrm{CF}_{3}$ substituent at $\mathrm{C} 2$ position was found to be the most toxic [27]. From the above information, it can be inferred that the substitution at N10 position seems to have a more profound effect than that of $\mathrm{C} 2$ position in the manifestation of cytotoxicity in HTC cell line. Formation of cation derived species may handle PTZ induced cytotoxicity and cell death. HOMO energy is the energy required to remove one electron from a molecule. Formation of cation derived species depends on HOMO energy. Both TR and TFP have electron donating group $\left(\mathrm{SCH}_{3}\right)$ and TFPZ has electron withdrawing group $\left(\mathrm{CF}_{3}\right)$. Therefore, the HOMO energy of the former are lower than that of the later. This indicates that there is a possibility of cation-radical formation in PTZs which may account for cytotoxicity [24]. Further research is needed to elucidate the participation of PTZ cation-radical species. PTZs induced the reduction of mitochondrial membrane potential in HTC cells followed the same order of potency as PTZs exhibited for the toxicity that indicates that the cytotoxicity resulted in mitochondrial-mediated cell death [24].

L-Dihydroxyphenylalanine (L-DOPA) is administered to patients suffering from Parkinson's diseases. Neurotoxicity associated with Parkinson's disease is intricately related to dopamine oxidation giving rise to free radicals and quinone species [28]. This leads to oxidative stress and can induce various forms of mitochondrial dysfunctions $[29,30]$. Dopamine is first converted to dopamine quinone that in turn undergoes one electron oxidation to form dopamine o-semiquinone (Figure 4). The semiquinone form can disproportionate to generate dopamine o-quinone that ultimately cyclizes to generate aminochrome [31]. Aminochrome forms adducts with $\alpha$-synuclein leading to the formation of neurotoxic protofilaments [32]. These dopamine derived quinones have high reactivity towards NADH and GSH and contribute to the underlying mechanism of oxidative stress-induced mitochondrial dysfunction in the pathophysiology of Parkinson's disease [33].

1-Methyl-4-Phenyl-1,2,3,6-Tetrahydro Pyridine (MPTP), present in the synthetic heroin, is a potent inducer of Parkinson's disease [34]. It undergoes oxidation and is converted to a potent neurotoxin, MPP [35]. MPP inhibits complex I in mitochondria of the dopaminergic neuron [36], leading to depletion of ATP [37] and increases production of ROS [38]. These phenomena ultimately lead to neuronal cell death [39]. Mitochondrial-targeted cytochrome P4502D6 (CYP2D6) along with adrenodoxin and adrenodoxin reductase plays a crucial role in the metabolism of MPTP to MPP+. MPTP treatment induces mitochondrial translocation of Parkin, an autophagic marker in differentiated neurons expressing mitochondrial targeted CYP2D6. This mitochondrial targeted CYP2D6 plays a pivotal role in the pathophysiology of Parkinson's disease [40].

\section{Berberine}

Berberine is the most abundant protoberberine alkaloid [41]. CYP enzymes, namely CYP2D6, CYP1A2 and CYP3A4, contribute to oxidative metabolism of this alkaloid and play a major role in the generation of berberine metabolites like demethyleneberberine, thalifendine. Demethyleneberberine is one of the most abundant metabolites generated through $\mathrm{NADH}$-dependent oxidation of berberine with the help of liver microsomal enzymes and hepatic P450s [42]. Palmatine, jatrorrhizine, demethyleneberberine, thalifendine and berberrubine, the metabolites of berberine cause metabolismdependent irreversible inactivation of CYP1B1 [43].

\section{Doxorubicin}

Doxorubicin is a widely used anticancer drug. This drug exerts its pharmacological effect in three ways. Firstly, the drug may insert into DNA strand of cancer cell and prevent DNA replication. Secondly, it may interfere with topoisomerase II, an enzyme involved in DNA replication. Finally doxorubicin can also generate free radical formation which generates oxidative stress in cancer cell. All these three mode of action of the drug ultimately lead to death of cancer cell.

During the metabolism of doxorubicin, ROS is produced in more than one ways. In the presence of $\mathrm{NADH}$, the quinone moiety of doxorubicin molecule is transformed into a semiquinone moiety via one-electron reduction mechanism by the complex I of the mitochondrial electron transport chain system [44]. The semiquinone moiety thus produced reacts with molecular oxygen to form a superoxide radical $\left(\mathrm{O}^{2-}\right)$, and doxorubicin molecule returns to its original quinone form. The cycling of this process between quinone and semiquinone forms generates a huge amounts of superoxide radical $\left(\mathrm{O}^{2-}\right)$. This in turn produces a variety of active $\mathrm{ROS} / \mathrm{RNS}$ species, including $\mathrm{H}_{2} \mathrm{O}_{2}, \cdot \mathrm{OH}$, and $\mathrm{ONOO}^{-}$[45]. Some endogenous reductases and the endothelial isoform of nitric oxide synthase, present in heart tissue, help in catalyzing the redox cycling of doxorubicin.

Doxorubicin also interferes with iron used for normal metabolic reactions and produces ROS. Doxorubicin semiquinone moiety, $\mathrm{O}^{2-}$, and their byproduct $\mathrm{H}_{2} \mathrm{O}_{2}$ helps in the release of iron from ferritin, which is an useful iron-storage protein [46] and cytoplasmic aconitase, where $[4 \mathrm{Fe}-4 \mathrm{~S}]$ cluster is present. Due to the loss of [4Fe-4S] cluster cytoplasmic aconitase is converted into iron regulatory protein (IRP)1 which subsequently binds with strong affinity to conserve ironresponsive elements (IRE) in the un-translated regions of transferrin receptor (TfR) [45]. As a result of this, iron uptake exceeds iron sequestration and increase in cellular levels of free iron take place which leads to the more production of ${ }^{\circ} \mathrm{OH}$ via Fenton chemistry reaction, ultimately leading to the oxidative stress and cytotoxicity.

Another important factor which contributes in ROS generation is the metabolic turnover of doxorubicin itself. The carbonyl group at $\mathrm{C} 13$ of aldoketo reductases is converted to a hydroxyl group, thereby

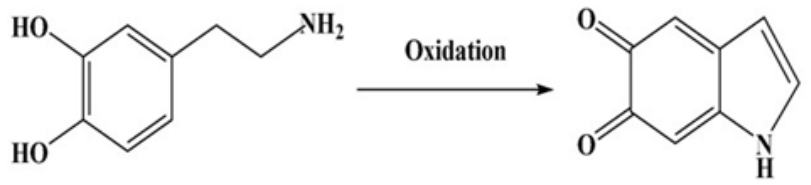

Dopamine

5,6-indolequinone

Figure 4: Formation of reactive metabolite from L-DOPA. 
inserting a secondary alcohol function in doxorubicin. This particular derivative is highly efficient in releasing iron from the [4Fe-4S] cluster of cytoplasmic aconitase, causing further imbalance in iron metabolism and impose oxidative stress. Doxorubicin can also be metabolized via the cleavage of the bond containing sugar residue of the parent compound into its aglycone form. Its lipophilic aglycone metabolite possesses a higher membrane diffusion capacity than doxorubicin moiety and can easily be accumulated in the inner mitochondrial membrane which leads to ROS formation and deterioration of the functional integrity of the respiration chain [45].

\section{Atorvastatin}

Atorvastatin, a member of statin drug family, is the most popularly used 3-hydroxy-3-methylglutaryl coenzyme A (HMG-CoA) reductase inhibitor [47]. It is an important enzyme in the synthesis of cholesterol and is considered to take part in the rate limiting step of this particular synthesis. High level of cholesterol is a risk factor for coronary disease and atherosclerosis [48]. Atorvastatin undergoes metabolism in hepatic tissue and generates reactive toxic metabolites [49]. Oxidative metabolism of this drug through CYP3A4 leads to the formation of hydroxylated acid metabolites, 4-hydroxy-atorvastatin acid and 2-hydroxy-atorvastatin acid [47,50]. The hydroxyl derivatives are converted to lactone metabolites through CYP3A4 mediated metabolism. The lactone and hydroxylated metabolites can interconvert themselves through hydrolysis and lactonization [51]. The formation of atorvastatin lactone is regulated via UGT1A1 and UGT1A3 mediated metabolism and that of 2-hydroxy-atorvastatin acid is regulated by CYP3A4 and CYP2C8 mediated metabolism [52]. Statins are often administered with other drugs because many patients, suffering from hyperlipidemia, also suffer from coronary heart diseases and diabetic complications. So there is a high chance of adverse drugdrug interaction $[53,54]$.

The oxidative metabolism of atorvastatin and generation of reactive metabolites must be considered for a reliable prediction of drug disposition, especially when this drug is administered with other drugs. The inter conversion among hydroxylated and lactone form plays an integral role in drug-drug interaction [55,47].

Gene expression profiling of two statin drugs (fluvastatin and atorvastatin), having the ability to form toxic reactive $\mathrm{p}$-quinoneimine intermediates, showed changes in the expression of 857 and 1091 transcripts, respectively. However, only 102 transcripts were differentially expressed in case of simvastatin because this drug cannot form aminophenol intermediate due to lack of nitrogen and an arene ring. The differentially expressed targeted genes related mostly to cell death, cell cycle regulation, metabolism and cell defense [56,57].

Pal et al. evaluated the toxic mechanism of atorvastatin in mouse liver. Atorvastatin has been shown to enhance the level of ALP and ALT in hepatic tissue indicating hepatic damage. ROS and oxidative stress played the pivotal role in this hepatotoxicity. Administration of the drug led to the phosphorylation of stress responsive MAPKinse, JNK, p38 and ERK. Also, oxidative stress induced endoplasmic-reticulum stress mediated apoptosis through caspase 12 and mitochondria mediated intrinsic pathway of apoptosis (Figures 5 and 6) [58].

\section{Role of Drug Metabolizing Enzymes in Disease}

Cytochrome P450 belongs to the largest superfamilies of enzymes involved in the biotransformation of drugs, xenobiotics and endogenous molecules [59]. Metabolites generated via CYP-mediated metabolism of endogenous substances play crucial roles in the origin and progression of many diseases. Oxidative stress mediated metabolic dysfunction of adipose tissue leads to obesity and cardiovascular diseases [60,61].

Arachidonic acid metabolism is a very important phenomenon in vascular tone [62]. 20-Hydroxy-5, 8, 11, 14-eicosatetraenoic acid (20 HETE) is formed by omega-hydroxylation of this molecule, and this reaction is catalyzed by cytochrome P450. 20 HETE induces oxidative stress via the stimulated generation of superoxide radicals. It inhibits the expression of endothelial nitric oxide synthase (eNOS) and increases the expression of pro-inflammatory cytokines $[63,64]$<smiles>CC(C)c1c(C(=O)Nc2ccccc2)c(-c2ccccc2)c(-c2ccc(F)cc2)n1CCC(O)CC(O)CC(=O)O</smiles>

Atorvastatin

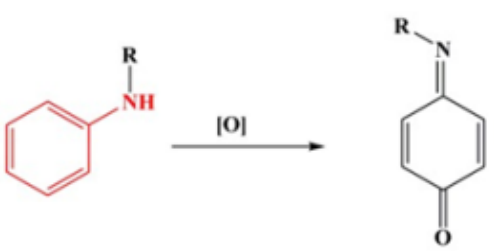

aniline-analog

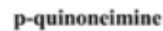

Figure 5: Structure of atorvastatin and generation of quinine metabolite.

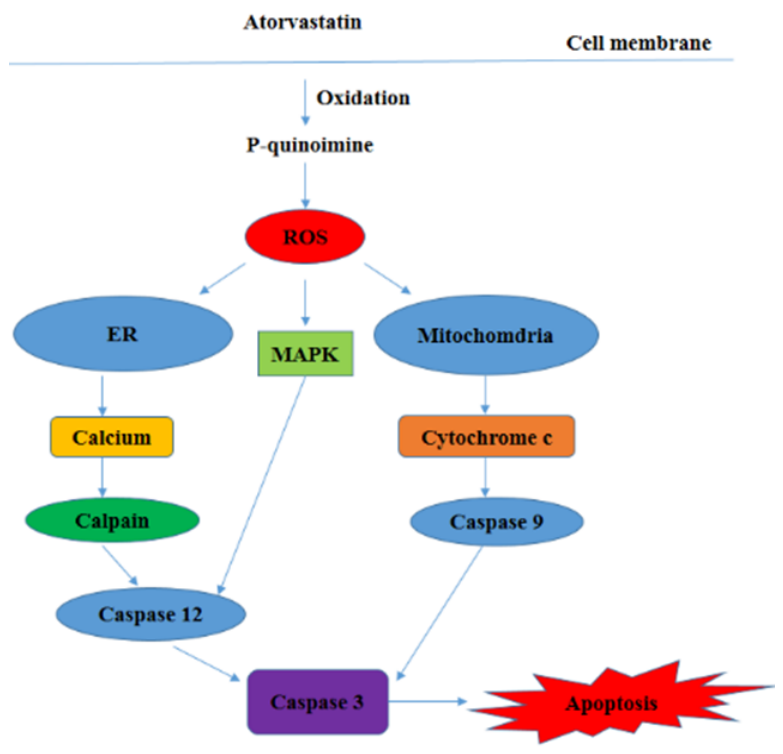

Figure 6: Mechanism of cellular toxicity by atorvastatin. 
Kim et al. investigated the effect of 20 HETE on mesenchymal stem cells (MSC) as these cells differentiate into adipocytes. Expression of two major 20 HETE synthase enzymes, CYP4A11, and CYP4E2, are found to be decreased in MSC at the time of adipocyte differentiation. Exogenous administration of 20 HETE increases the differentiation of MSC in a dose-dependent manner in association with increased expression of PPAR $\gamma$ and $\beta$ catenin. This study clearly demonstrates that 20 HETE increases mature inflamed adipocyte hypertrophy [65].

The rennin-angiotensin system plays a key role in maintaining cardiac homeostasis by generating angiotensin II (ANG II) [66]. Excess production of ANG II leads to hypertension [67], inflammation, ROS production and endothelial dysfunction [68]. The arachidonic acid metabolite, 20 HETE also helps to mediate ANG II-induced vasoconstriction [69], and CYP4A has been reported to be involved in this mechanism [70,71]. CYP1E1, expressed highly in cardiovascular tissue, can also generate 20 HETE from arachidonic acid and generate ROS [72]. A recent report suggests that ANG II infusion increases renal CYP1B1 activity and endothelial dysfunction in CYP1B1+/+ mice compared to CYP1B1-/- mice [73] and CYP1B1 activity in renal tissue. This infusion with ANG II also increases ROS production, NADPH oxidase activity and the levels of ERK1/2 and p38 MAPK. CYP1B1 can be used as a therapeutic target to treat hypertension associated renal disease.

\section{Endogenous Antioxidant Mechanism}

It is apparent from the above-mentioned points that the reactive molecules generated during CYP450 mediated metabolism of drugs cause oxidative stress and led to a pathophysiological response. The balance between pro and anti-oxidants get disrupted during oxidative stress. To resume the fine balance and to restore homeostasis, molecules related to stress response get activated. These molecules play a key role in detoxification of toxic substances. One such endogenous molecule is NF-E2-related factor 2 (NRF2) transcription factor [74,75]. Under normal physiological conditions (unstressed conditions), this transcription factor is sequestered in the cytosol by a molecule called keap1. keap1 is an ubiquitin ligase that degrade NRF2 under normal conditions $[76,77]$. During oxidative stress, excessive ROS production leads to oxidation of distinct cysteine residue of keap1 that leads to conformational changes of the protein such that it can no longer bind to NRF2, and proteasomal degradation of NRF2 is prevented [78]. NRF2 then translocates to the nucleus and binds to DNA sequence of antioxidant response genes for transcription and subsequently involves the activation of other antioxidant response genes like NQO-1, NQO2 , Heme oxygenase $1(\mathrm{HO}-1)$, etc.

Quinone metabolites [such as 1,4-Benzoquinone (BQ) and aminochrome] have been reported to induce endoplasmic reticulum stress (ER stress) and autophagy in dopaminergic N27 cells; however, overexpression of NQO1 can protect the cells against apoptosis and ER stress [79]. NRF2 plays a major role in protecting neuronal cells against 6-hydroxydopamine toxicity [80]. A $\beta$-lapachone analogue (3,4-dihydro-2,2-dimethyl-9-chloro-2H-naphtho[1,2b] pyran-5,6dione) (9-chloro $\beta$-lapachone), named CGQ is known to possess antitumour and anti- viral activities. This compound causes hepatic toxicity by depleting GSH and producing more superoxide radicals resulting oxidative stress. NQO1 helps in detoxification of toxic metabolites and rescues the hepatic cells from oxidative stress [81].

Aryl hydrocarbon Receptor (AhR) is a transcription factor that has pleiotropic activities and is involved in detoxification of endo and xenobiotics [82]. AhR translocates to the nucleus after ligand binding and association with aryl hydrocarbon receptor nuclear translocator (Arnt). This heterodimer then binds to xenobiotic response elements and transcribes genes responsible for detoxification of toxic metabolites. $\mathrm{AhR}$ is also reported to be involved in xenobiotic detoxification in lung tissues [83].

\section{Antioxidant Therapy}

From the above-mentioned points, it is transparent that reactive metabolites formed during drug metabolism generate oxidative stress. Though endogenous defense molecular mechanism plays a big role to circumvent oxidative stress-mediated damage, but excessive ROS generation can overcome endogenous defense mechanism. For this reason, administration of antioxidant molecules can prove to be beneficial.

Resveratrol, a natural antioxidant phytoestrogen exerts protective effect estrogen induced breast cancer through NRF2 mediated upregulation of antioxidant molecules like NQO1, superoxide dismutase 3 (SOD3) [84].

Mangiferin (2-C- $\beta$-D-glucopyranosyl-1,3,6,7-tetrahydroxyxanthone), a naturally occurring polyphenol is present in leaves, roots and barks of plants belonging to Anacardiaceae and Gentianaceae families (e.g. Mangifera indica, mango) [85]. This molecule was found to ameliorate galactosamine-induced hepatic toxicity, reduced ROS and nitric oxide (NO) formation. Expression of NADPH:quinone oxidoreductase-1, heme oxygenase-1, GSTa and NRF2 were restored by mangiferin treatment [86] This natural antioxidant also attenuated lead induced hepatic toxicity and cell death via modulation of MAPKinase pathway and antioxidant machinery [87].

Taurine (2-aminoethanesulfonic acid), ameliorated alloxan induced diabetic nephropathy by decreasing blood glucose level, the level of pro-inflammatory cytokines. It also reduced renal oxidative stress by reducing activity of xanthine oxidase and inhibition of $\mathrm{p} 47 \mathrm{phox} /$ CYP2E1 pathways [88]. This molecule protects testis from doxorubicininduced damage. Taurine restored the activities of catalase, superoxide dismutase, glutathione reductase and glutathione S-transferase thereby reducing oxidative stress. Also it also ameliorated endoplasmic reticulum stress mediated testicular cell death [89]. Taurine has shown to exert a protective effect in the liver against acetaminopheninduced oxidative damage [90]. This molecule also protects against arsenic mediated hepatic and cardiac damage, also sodium fluoride mediated toxicity in murine hepatocytes [91-93]. Curcumin and quercetin treatment decreased ROS formation, activities of GST, SOD. Expression and activities of drug metabolizing enzymes cytochrome $\mathrm{P} 450$ and b5 were also reduced by treatment with these two polyphenols in benzo(a)pyrene induced lung carcinogenesis [94]. Quercetin has been proved to be effective against fluoride-induced oxidative stress in multiple organs like liver, kidney, testis and brain [95]. Curcumin protects microglial cells by induction of antioxidant gene $\mathrm{HO}-1$ and reducing inflammation [96]. This polyphenol also ameliorates diabetes induced multiple organ pathophysiologies [97-100]. Morin, another polyphenol ameliorates NSAID-induced gastropathy [101]. A novel protein isolated from a plant Phyllanthus niruri ameliorated aspirininduced toxicity in liver and spleen [102]. Arjunolic acid attenuated sodium nitrite-induced cardiac pathophysiology by modulating pro and inflammatory cytokines, extrinsic and intrinsic apoptotic pathways and also ameliorated sodium fluoride induced renal and hepatic oxidative stress $[103,104]$. This molecule ameliorates doxorubicininduced cardiac toxicity [105]. Arjunolic acid also exerts its beneficial role in type I diabetes [106-108]. This molecule also protects liver and 
kidney from atorvastatin mediated toxicity [109]. Studies suggest that antioxidant therapy can be effective in oxidative stress-mediated cellular toxicity during drug metabolism.

Studies conducted on animal models have shown that antioxidant therapy can be effective in combating oxidative stress mediated cytotoxicity, however, there are some side effects associated with antioxidant therapy. Curcumin is a well-known anti-oxidant and antiinflammatory molecule, but long time administration of curcumin may chelate dietary trace elements leading to adverse effects. Six months of dietary supplementation with $0.2 \%$ curcumin lead to iron deficiency in C57BL/6J mice. Reduced expression of ferritin and hepcidin in the liver of curcumin supplemented animals were also observed.

Chin et al. have demonstrated that long-term supplementation of curcumin with western diet (20\% fat and $10 \%$ sugar) aggravate iron deficiency probably through chelation of iron [110]. The major problem of curcumin relates to its poor bioavailability. To improve the bioavailability of curcumin, nano-curcumin and nano-vector for delivery of hydrophobic molecules have come into scenario [105]. The clinical trial was carried out with THERACURMIN, a nanoparticlebased curcumin in pancreatic cancer patients. Sixteen cancer patients (14 patients having pancreatic cancer and two patients having biliary tract cancer) were enrolled for the clinical trial. These patients failed to respond to standard gemcitabine-based chemotherapy. Two patients showed abdominal pain on administration of THERACURMIN [111]. Epelbaum et al. also reported that patients suffer from abdominal fullness and abdominal pain following curcumin administration [112]. Genistein is a phytoestrogen that possess pleiotropic activities like anti-oxidant, anti-inflammatory, anti-diabetic, anti-cancer, etc [113]. Reports suggest that genistein causes altered ovarian development, ovulation and estrous cycle $[114,115]$.

\section{Recent Trends and Conclusion}

Pharmaceutical industry, now-a-days, is trying to deliver safe and effective medicines by reducing operating costs and cycle times for drug development to improve the existing therapies in terms of efficacy and safety. One of the most significant challenges to face these demands is the unpredictable nature of the most forms of drug toxicity which arises due to the oxidative stress during drug metabolism and frequently leads to the failure of new drug candidates preclinical toxicity testing. This failure is directly related to the acute, sub chronic, or chronic toxicity testing stages. Many target organ toxicities can be identified in the preclinical stage of safety evaluation; some adverse effects mediated via oxidative stress mechanism, practically remain unknown during animal experiments. These idiosyncratic toxicities do not usually occur and can only be identified during large scale clinical trials. However, this situation creates a negative impact as a significant amount of money has already been spent into the drug candidate. The scenario becomes even worse, if a compound needs to be withdrawn after it has been introduced into the market. From the point of view of both the patient safety and economic loss to the sponsor company, this unpredictable nature of the drug toxicity is, therefore, a great concern [116]. Researchers are actively investigating to get rid of this situation. It may be avoided by the inhibition of toxic metabolites formation or by some structural modification that could ameliorate the toxicity induced by the metabolites. For example, carbamazepine is an anticonvulsant and analgesic drug. Its derivative, oxcarbazepine, developed by the structural modification of carbamazepine to avoid the oxidative-metabolism induced side effects, is also an anticonvulsant and mood-stabilizing drug, primarily used for the epilepsy treatment [117]. Carbamazepine is oxidised by CYP system and oxcarbazepine undergoes reduction of the keto moiety and forms 10-monohydroxy derivative. Another such example is aflatoxin. Aflatoxin B1 is well established mycotoxin. Guengerich et al. has established the mechanism for the metabolism of the mycotoin via CYP mechanism. It was suggested that during the metabolism, the mycotoxin is converted into an exo epoxide and an endo epoxide in which the exo compound is mostly toxic but it could be modulated by conjugation with GST $[5,118]$.

Another aspect to reduce the drug toxicity is the inhibition of the drug metabolizing enzymes. Inhibition of the drug metabolizing enzymes is an interest field of interest to most of the pharmacologists, enzymologists and clinicians. Two main practical applications on the knowledge of inhibition of drug metabolizing enzymes are required in the pharmaceutical industry. First one is drug-drug interaction, i.e., one drug may interact and inhibit the biotransformation of another when these two are taken simultaneously. In pharmacotherapy, these drug interactions are of major concern. Because of fatal interactions, several important drugs have been withdrawn from the market as those have been reported to cause serious adverse effects related to drug interactions [117-121]. Probably, the most common cause for documented drug interactions is either induction or inhibition of cytochrome P450 enzymes [121]. Unsafe elevations in the plasma concentrations of drugs could be the result of the inhibition of metabolism due to the competition of the drugs for the same enzyme and this can lead to serious adverse effects as well as toxicities [121]. On the other hand, because of the enzyme induction, the rate of drug elimination and attenuation of its pharmacological effect can be increased as a result of the decreased plasma concentration [121]. Here it is worth mentioning that except CYP2D6, all other isoforms of the CYPs involved in drug metabolism, are inducible enzymes and can be induced by exogenous chemicals and even some endogenous factors [116].

Drug metabolism issues also have a close relation with the clinical trial of drugs. The aim of the clinical trials is to determine the toxicity and the efficacy of certain drugs in the cellular system [5]. New information related to the interaction of drugs with other molecules, formation of reactive metabolites, also the nature of its toxicity can be obtained from these studies. Undesirable toxic reactions reduce the efficacy of the drugs; elimination or at least reduction of those can enhance the same. In addition, the diversity of drug metabolizing enzymes has been reported to play a significant role in drug toxicity. For example, allelic variants with different catalytic activities of CYP enzymes can be expected to be responsible for the drug toxicity. Although the degrees of toxicity of all the isoforms are not the same, studies suggest that certain drugs are highly toxic in some populations due to a heritable deficiency in the CYP450 enzymes. Both CYP2D6 and CYP2C19 are expressed in a polymorphic manner. However, CYP2C19 has at least 70 single nucleotide polymorphisms (SNPs) [5]. It can, therefore, be said that an individual obviously suffers from poor metabolism of certain drugs because of the lacking a particular CYP gene and face the consequences of drug toxicity. Now-a-days, combination of pharmacogenetics and human genomics is providing sufficient knowledge on genetic variations and helps controlling the variability in drug response as well as the associated toxicity [122]. The sequence variation in the proteins targeted by any drug has pronounced effect on the potency as well as side effects of that drug and is strongly regulated by their drug-metabolizing enzymes and transporters. Combining, we say, these factors play the most crucial role for the variable drug responses in individuals [123-129]. 
Both the drug efficacy and toxicity depend on the optimum dose of a particular drug. Sometimes it has been observed that the optimum treatment necessary for productive and safe therapy diverges significantly from patient to patient. Therefore, if the dose of the drug is not applied accordingly, the clinical result may change. On the other hand, a particular drug response in an individual, both the genetic and non-genetic factors are responsible for this effect [5]. Genetic polymorphisms of proteins are considered to be the major determinants of the metabolism of drugs. In case of non-genetic factor, the normal condition may return whenever the factor is removed [123]. Drug target is responsible for adverse drug reaction, which results in two types of side effects i.e. on-target as well as off-target side effects. Pharmacokinetics variations sometimes alter the concentration of a toxic drug or metabolite in the target tissue [123] and which ultimately results in variable toxicity. Some genetic changes have direct or indirect effect on both drug efficacy and drug safety and this type of divergence may modulate the biological context in which a particular drug reaction occurs [5].

The formation of the active metabolites during drug metabolism mainly depends on the balance among the various CYP enzymes. For example, the bio-activation process of clopidogrel (to date, second most prescribed drug which is used to inhibit blood clots in coronary artery disease, peripheral vascular disease, and cerebrovascular disease $[5,129]$ depends on the balance of many CYP enzymes (CYP2C19, CYP1A2, CYP2B6, CYP3A4 and CYP2C9). Similarly, Jin et al. showed that the bio-activation of tamoxifen also mediated via the cooperation among the CYP enzymes. Combining, we would like to say that pharmacogenomics guided drug development is essential for promoting efficient, safe, widely applicable and cost-effective drug therapy.

\section{Acknowledgements}

The authors are grateful to Mr. Sudip Bhattacharyya and Mr. Shatadal Ghosh for their immense help in technical correction and preparation of figures.

\section{References}

1. Deavall DG, Martin EA, Horner JM, Roberts R (2012) Drug-induced oxidative stress and toxicity. J Toxicol 2012: 645460.

2. Rowland A, Miners JO, Mackenzie PI (2013) The UDP-glucuronosyltransferases: their role in drug metabolism and detoxification. Int $\mathrm{J}$ Biochem Cell Biol 45: 1121-1132.

3. Gandhi A, Moorthy B, Ghose R (2012) Drug disposition in pathophysiological conditions. Curr Drug Metab 13: 1327-1344.

4. Zangar RC, Davydov DR, Verma S (2004) Mechanisms that regulate production of reactive oxygen species by cytochrome P450. Toxicol Appl Pharmacol 199: 316-331.

5. Bhattacharyya S, Sinha K, Sil PC (2014) Cytochrome P450s: Mechanisms and biological implications in drug metabolism and its interaction with oxidative stress. Curr Drug Metab 15: 719-742.

6. Bock KW (2012) Ah receptor- and Nrf2-gene battery members: modulators of quinone-mediated oxidative and endoplasmic reticulum stress. Biochem Pharmacol 83: 833-838.

7. Turrens JF, Boveris A (1980) Generation of superoxide anion by the NADH dehydrogenase of bovine heart mitochondria. Biochem J 191: 421-427.

8. Sinha K, Das J, Pal PB, Sil PC (2013) Oxidative stress: the mitochondriadependent and mitochondria-independent pathways of apoptosis. Arch Toxicol 87: 1157-1180.

9. Liu Y, Vinje J, Pacifico C, Natile G, Sletten E (2002) Formation of adenine-N3/ guanine-N7 cross-link in the reaction of trans-oriented platinum substrates with dinucleotides. J Am Chem Soc 124: 12854-12862.

10. Yang P, Ma J, Zhang B, Duan H, He Z, et al. (2012) CpG site-specific hypermethylation of p16INK4Î in peripheral blood lymphocytes of PAH-exposed workers. Cancer Epidemiol Biomarkers Prev 21: 182-190.

11. Barouki R, Morel Y (2001) Repression of cytochrome P4501A1 gene expression by oxidative stress: mechanisms and biological implications. Biochem Pharmacol 61: 511-516.

12. Bondy SC, Naderi S (1994) Contribution of hepatic cytochrome P450 systems to the generation of reactive oxygen species. Biochem Pharmacol 48: 155-159.

13. Mazer M, Perrone J (2008) Acetaminophen-induced nephrotoxicity: pathophysiology, clinical manifestations, and management. J Med Toxicol 4 2-6.

14. Henderson NC, Pollock KJ, Frew J, Mackinnon AC, Flavell RA, et al. (2007) Critical role of c-jun (NH2) terminal kinase in paracetamol- induced acute liver failure. Gut 56: 982-990.

15. Yang X, Salminen WF, Shi Q, Greenhaw J, Gill PS, et al. (2015) Potential of extracellular microRNAs as biomarkers of acetaminophen toxicity in children. Toxicol Appl Pharmacol 284: 180-187.

16. Marques MM, Beland FA (1997) Identification of tamoxifen-DNA adducts formed by 4-hydroxytamoxifen quinone methide. Carcinogenesis 18: 19491954.

17. Hemachandra LP, Patel H, Chandrasena RE, Choi J, Piyankarage SC (2014) SERMs attenuate estrogen induced malignant transformation of human mammary epithelial cells by upregulating detoxification of oxidative metabolites. Cancer Prev Res (Phila) 5: 505-515.

18. Sumi D, Numasawa $Y$, Endo A, Iwamoto N, Kumagai $Y$ (2009) Catechol estrogens mediated activation of Nrf2 through covalent modification of its quinone metabolite to Keap1. J Toxicol Sci 34: 627-635.

19. Dragovic S, Gunness $P$, Ingelman-Sundberg M, Vermeulen NP, Commandeur JN (2013) Characterization of human cytochrome P450s involved in the bioactivation of clozapine. Drug Metab Dispos 41: 651-658.

20. Li X, Cameron MD (2012) Potential role of a quetiapine metabolite in quetiapineinduced neutropenia and agranulocytosis. Chem Res Toxicol 25: 1004-1011.

21. Small JG, Hirsch SR, Arvanitis LA, Miller BG, Link CG (1997) Quetiapine in patients with schizophrenia. A high- and low-dose double-blind comparison with placebo. Seroquel Study Group. Arch Gen Psychiatry 54: 549-557.

22. Bowden CL, Grunze H, Mullen J, Brecher M, Paulsson B, et al. (2005) A randomized, double-blind, placebo-controlled efficacy and safety study of quetiapine or lithium as monotherapy for mania in bipolar disorder. $\mathrm{J}$ Clin Psychiatry 66: 111-121.

23. MacAllister SL, Young C, Guzdek A, Zhidkov N, O'Brien PJ (2013) Molecula cytotoxic mechanisms of chlorpromazine in isolated rat hepatocytes. Can J Physiol Pharmacol 91: 56-63.

24. De Faria A, Bettanin F, Cunha R, Gamero E, et al. (2015) Cytotoxicity of phenothiazine derivatives associated with mitochondrial dysfunction: A structure-activity investigation. Toxicology 330: 44-54.

25. Andrade RJ, Robles M, Fernández-Castañer A, López-Ortega S, López-Vega $\mathrm{MC}$, et al. (2007) Assessment of drug-induced hepatotoxicity in clinical practice: a challenge for gastroenterologists. World J Gastroenterol 13: 329-340.

26. Brind AM (2007) Drugs that damage the liver. Medicine 35: 26-30

27. Zhelev Z, Ohba H, Bakalova R, Hadjimitova V, Ishikawa M, et al. (2004) Phenothiazines suppress proliferation and induce apoptosis in cultured leukemic cells without any influence on the viability of normal lymphocytes. Cancer Chemother Pharmacol 53: 267-275

28. Graham DG (1978) Oxidative pathways for catecholamines in the genesis of neuromelanin and cytotoxic quinones. Mol Pharmacol 14: 633-643.

29. Gluck MR, Zeevalk GD (2004) Inhibition of brain mitochondrial respiration by dopamine and its metabolites: implications for Parkinson's disease and catecholamine-associated diseases. J Neurochem 91: 788-795.

30. Berman SB, Hastings TG (1999) Dopamine oxidation alters mitochondria respiration and induces permeability transition in brain mitochondria implications for Parkinson's disease. J Neurochem 73: 1127-1137.

31. Segura-Aguilar J, Metodiewa D, Welch CJ (1998) Metabolic activation of dopamine o-quinones to o-semiquinones by NADPH cytochrome P450 reductase may play an important role in oxidative stress and apoptotic effects. Biochim Biophys Acta 1381: 1-6. 
Citation: Banerjee S, Ghosh J, Sil PC (2016) Drug Metabolism and Oxidative Stress: Cellular Mechanism and New Therapeutic Insights. Biochem Anal Biochem 5: 255. doi:10.4172/2161-1009.1000255

Page 9 of 11

32. Muñoz P, Huenchuguala S, Paris I, Segura-Aguilar J (2012) Dopamine Oxidation and Autophagy Parkinson Dis 2012: 920-953.

33. Bisaglia M, Soriano ME, Arduini I, Mammi S, Bubacco L (2012) Molecula characterization of dopamine-derived quinones reactivity toward $\mathrm{NADH}$ and glutathione: Implications for mitochondrial dysfunction in Parkinson disease. Biochim Biophys Acta 1802: 699-706.

34. Kopin IJ, Markey SP (1988) MPTP toxicity: implications for research in Parkinson's disease. Annu Rev Neurosci 11: 81-96.

35. Chiba K, Peterson LA, Castagnoli KP, Trevor AJ, Castagnoli N Jr (1985) Studies on the molecular mechanism of bioactivation of the selective nigrostriatal toxin 1-methyl-4-phenyl-6-tetrahydropyridine. Drug Metab Dispos 13: 342-347.

36. Ramsay RR, Kowal AT, Johnson MK, Salach JI, Singer TP (1987) The inhibition site of MPP+, the neurotoxic bioactivation product of 1-methyl-4-phenyl-6tetrahydropyridine is near the Q-binding site of NADH dehydrogenase. Arch Biochem Biophys 259: 645-649.

37. Di Monte D, Jewell SA, Ekström G, Sandy MS, Smith MT (1986) 1-Methyl4-phenyl-6-tetrahydropyridine (MPTP) and 1-methyl-4-phenylpyridine (MPP+) cause rapid ATP depletion in isolated hepatocytes. Biochem Biophys Res Commun 137: 310-315

38. Hasegawa E, Takeshige K, Oishi T, Minakami S (1990) Methyl-4phenylpyridinium (MPTP) induces NADH-dependent superoxide formation and enhances NADH-dependent lipid peroxidation in bovine heart submitochondrial particles. Biochem Biophys Res Commun 170: 1049-1055.

39. Bloem BR, Irwin I, Buruma OJ, Haan J, Roos RA, et al. (1990) The MPTP model: versatile contributions to the treatment of idiopathic Parkinson's disease. J Neurol Sci 97: 273-293.

40. Bajpai P, Sangar MC, Singh S, Tang W, Bansal S, et al. (2013) Metabolism of 1-methyl-4-phenyl-6-tetrahydropyridine by mitochondrion-targeted cytochrome P450 2D6: implications in Parkinson disease. J Biol Chem 288: 4436-4451.

41. Kulkarni SK, Dhir A (2010) Berberine: a plant alkaloid with therapeutic potentia for central nervous system disorders. Phytother Res 24: 317-324.

42. Li Y, Ren G, Wang YX, Kong WJ, Yang P, et al. (2011) Bioactivities of berberine metabolites after transformation through CYP450 isoenzymes. J Transl Med 9 : 62.

43. Lo SN, Shen CC, Chang CY, Tsai KC, Huang CC, et al. (2015) The Effect of oxidation on berberine-mediated CYP1 inhibition: Oxidation behavior and metabolite-mediated inhibition. Drug Metab Dispos 43: 1100-1107.

44. Marcillat O, Zhang Y, Davies KJ (1989) Oxidative and non-oxidative mechanisms in the inactivation of cardiac mitochondrial electron transport chain components by doxorubicin. Biochem J 259: 181-189.

45. Chen Y, Jungsuwadee P, Vore M, Butterfield DA, St Clair DK (2007) Collatera damage in cancer chemotherapy: oxidative stress in nontargeted tissues. Mol Interv 7: 147-156.

46. Minotti G, Menna P, Salvatorelli E, Cairo G, Gianni L (2004) Anthracyclines: molecular advances and pharmacologic developments in antitumor activity and cardiotoxicity. Pharmacol Rev 56: 185-229.

47. Zhang T (2015) Physiologically based pharmacokinetic modeling of disposition and drug-drug interactions for atorvastatin and its metabolites. Eur $\mathrm{J}$ Pharm Sci 77: 216-229

48. Smith MEB, Lee, N.J., Haney E, Carson S (2009) Drug Class Review: HMG CoAReductase Inhibitors (Statins) and Fixed-dose Combination Products Containing a Statin: Final Report Update 5. Portland

49. Stamper BD (2015) Transcriptional profiling of reactive metabolites for elucidating toxicological mechanisms: a case study of quinoneimine-forming agents. Drug Metab Rev 47: 45-55.

50. Jacobsen W, Kuhn B, Soldner A, Kirchner G, Sewing KF, et al. (2000) Lactonization is the critical first step in the disposition of the 3-hydroxy-3methylglutaryl-CoA reductase inhibitor atorvastatin. Drug Metab Dispos 28 1369-1378.

51. Li C, Subramanian R, Yu S, Prueksaritanont T (2006) Acyl-coenzyme formation of simvastatin in mouse liver preparations. Drug Metab Dispos 34: 102-110.

52. Prueksaritanont T, Subramanian R, Fang X, Ma B, Qiu Y, et al. (2002) Glucuronidation of statins in animals and humans: a novel mechanism of statin lactonization. Drug Metab Dispos 30: 505-512.
53. Egger SS, Rätz Bravo AE, Hess L, Schlienger RG, Krähenbühl S (2007) Agerelated differences in the prevalence of potential drug-drug interactions in ambulatory dyslipidaemic patients treated with statins. Drugs Aging 24: 429440

54. Davidson $\mathrm{MH}$ (2006) Statin/fibrate combination in patients with metabolic syndrome or diabetes: evaluating the risks of pharmacokinetic drug interactions. Expert Opin Drug Saf 5: 145-156.

55. Hirota T, leiri I (2015) Drug-drug interactions that interfere with statin metabolism. Expert Opin Drug Metab Toxicol 11: 1435-1447.

56. Hafner M, Juvan P, Rezen T, Monostory K, Pascussi JM, et al. (2011) The human primary hepatocyte transcriptome reveals novel insights into atorvastatin and rosuvastatin action. Pharmacogenet Genomics 21: 741-750.

57. Schröder A, Wollnik J, Wrzodek C, Dräger A, Bonin M, et al. (2011) Inferring statin-induced gene regulatory relationships in primary human hepatocytes. Bioinformatics 27: 2473-2477.

58. Pal S, Ghosh M, Ghosh S, Bhattacharyya S, Sil PC2 (2015) Atorvastatin induced hepatic oxidative stress and apoptotic damage via MAPKs, mitochondria calpain and caspase12 dependent pathways. Food Chem Toxicol 83: 36-47.

59. Gonzalez FJ (1990) Molecular genetics of the P-450 superfamily. Pharmaco Ther 45: 1-38.

60. Hung WW, Hsieh TJ, Lin T, Chou PC, Hsiao PJ, et al. (2011) Blockade of the renin-angiotensin system ameliorates apelin production in 3T3-L1 adipocytes. Cardiovasc Drugs Ther 25: 3-12.

61. Matsushita K, Wu Y, Okamoto Y, Pratt RE, Dzau VJ (2006) Local renin angiotensin expression regulates human mesenchymal stem cell differentiation to adipocytes. Hypertension 48: 1095-1102.

62. Sodhi K, Wu CC, Cheng J, Gotlinger K, Inoue K, et al. (2010) CYP4A2 induced hypertension is 20-hydroxyeicosatetraenoic acid- and angiotensin Itdependent. Hypertension 56: 871-878.

63. Ishizuka T, Cheng J, Singh H, Vitto MD, Manthati VL, et al. (2008) 20-Hydroxyeicosatetraenoic acid stimulates nuclear factor-kappaB activation and the production of inflammatory cytokines in human endothelial cells. Pharmacol Exp Ther 324: $103-110$

64. Cheng J, Ou JS, Singh H, Falck JR, Narsimhaswamy D, et al. (2008) 20-hydroxyeicosatetraenoic acid causes endothelial dysfunction via eNOS uncoupling. Am J Physiol Heart Circ Physiol 294: H1018-1026.

65. Kim DH, Puri N, Sodhi K, Falck JR, Abraham NG, et al. (2013) Cyclooxygenase-2 dependent metabolism of 20-HETE increases adiposity and adipocyte enlargement in mesenchymal stem cell-derived adipocytes. J Lipid Res 54: 786-793.

66. Kobori H, Nangaku M, Navar LG, Nishiyama A (2007) The intrarenal reninangiotensin system: from physiology to the pathobiology of hypertension and kidney disease. Pharmacol Rev 59: 251-287.

67. Csiky B, Simon G (1997) Effect of neonatal sympathectomy on development of angiotensin II-induced hypertension. Am J Physiol 272: H648-656.

68. Paravicini TM, Touyz RM (2008) NADPH oxidases, reactive oxygen species, and hypertension. Clinical implications and therapeutic possibilities. Diabetes Care Suppl 2: S170-180.

69. Alonso-Galicia M, Maier KG, Greene AS, Cowley AW Jr, Roman RJ (2002) Role of 20-hydroxyeicosatetraenoic acid in the renal and vasoconstricto actions of angiotensin II. Am J Physiol Regul Integr Comp Physiol 283: R60-68.

70. Muthalif MM, Karzoun NA, Gaber L, Khandekar Z, Benter IF, et al. (2000) Angiotensin II-induced hypertension: contribution of Ras GTPase/mitogenactivated protein kinase and cytochrome P450 metabolites. Hypertension 36 : 604-609.

71. Stec DE, Gannon KP, Beaird JS, Drummond HA (2007) 20-Hydroxyeicosatetraenoic acid (20-HETE) stimulates migration of vascular smooth muscle cells. Cell Physiol Biochem 19: 121-128.

72. Medhora M, Chen Y, Gruenloh S, Harland D, Bodiga S, et al. (2008) 20-HETE increases superoxide production and activates NAPDH oxidase in pulmonary artery endothelial cells. Am J Physiol Lung Cell Mol Physiol 294: L902-911.

73. Jennings BL, Anderson LJ, Estes AM, Yaghini FA, Fang XR, et al. (2012) Cytochrome P450 1B1 contributes to renal dysfunction and damage caused by angiotensin II in mice. Hypertension 59: 348-354. 
74. Kensler TW, Wakabayashi N, Biswal S (2007) Cell survival responses to environmental stresses via the Keap1-Nrf2-ARE pathway. Annu Rev Pharmacol Toxicol 47: 89-116

75. Kensler TW, Wakabayashi N (2010) Nrf2: friend or foe for chemoprevention? Carcinogenesis 31: 90-99.

76. Itoh K, Wakabayashi N, Katoh Y, Ishii T, Igarashi K, et al. (1999) Keap1 represses nuclear activation of antioxidant responsive elements by Nrf2 through binding to the amino-terminal Neh2 domain. Genes Dev 13: 76-86.

77. Kobayashi A, Kang MI, Okawa H, Ohtsuji M, Zenke Y, et al. (2004) Oxidative stress sensor Keap1 functions as an adaptor for Cul3-based E3 ligase to regulate proteasomal degradation of Nrf2. Mol Cell Biol 24: 7130-7139.

78. Yamamoto T, Suzuki T, Kobayashi A, Wakabayashi J, Maher J, et al. (2008) Physiological significance of reactive cysteine residues of Keap1 in determining Nrf2 activity. Mol Cell Biol 28: 2758-2770.

79. Xiong R, Siegel D, Ross D (2014) Quinone-induced protein handling changes: implications for major protein handling systems in quinone-mediated toxicity. Toxicol Appl Pharmacol 280: 285-295

80. Siebert A, Desai V, Chandrasekaran K, Fiskum G, Jafri MS (2009) Nrf2 activators provide neuroprotection against 6-hydroxydopamine toxicity in rat organotypic nigrostriatal cocultures. J Neurosci Res 87: 1659-1669.

81. Fernandez Villamil SH, Carrizo PH, Di Rosso ME, Molina Portela MP, Dubin M (2012) The metabolism of 9-chloro- $\left.\right|^{2}$-lapachone and its effects in isolated hepatocytes. The involvement of $\mathrm{NAD}(\mathrm{P}) \mathrm{H}$ :quinone oxidoreductase 1 (NQO1). Chem Biol Interact 200: 84-91.

82. Barouki R, Coumoul X, Fernandez-Salguero PM (2007) The aryl hydrocarbon receptor, more than a xenobiotic-interacting protein. FEBS Lett 581: 3608 3615.

83. Nebert DW, Shi Z, Gálvez-Peralta M, Uno S, Dragin N (2013) Oral benzo[a] pyrene: understanding pharmacokinetics, detoxication and consequences Cyp1 knockout mouse lines as a paradigm. Mol Pharmacol 84: 304-313.

84. Singh B, Shoulson R, Chatterjee A, Ronghe A, Bhat NK (2014) Resveratrol inhibits estrogen-induced breast carcinogenesis through induction of NRF2mediated protective pathways. Carcinogenesis 35: 1872-1880.

85. Yoshimi N, Matsunaga K, Katayama M, Yamada Y, Kuno T, et al. (2001) The inhibitory effects of mangiferin, a naturally occurring glucosylxanthone, in bowel carcinogenesis of male F344 rats. Cancer Lett 163: 163-170.

86. Das J, Ghosh J, Roy A, Sil PC (2012) Mangiferin exerts hepatoprotective activity against D-galactosamine induced acute toxicity and oxidative/nitrosative stress via Nrf2-NFkB pathways. Toxicol Appl Pharmacol 260: 35-47.

87. Pal PB, Sinha K, Sil PC (2013) Mangiferin, a natural xanthone, protects murine liver in $\mathrm{Pb}(\mathrm{II})$ induced hepatic damage and cell death via MAP kinase, NF-KB and mitochondria dependent pathways. PLoS One 8: e56894.

88. Das J, Sil PC (2012) Taurine ameliorates alloxan-induced diabetic renal injury, oxidative stress-related signaling pathways and apoptosis in rats. Amino Acids 43: $1509-1523$

89. Das J, Ghosh J, Manna P, Sil PC (2011) Taurine protects rat testes against doxorubicin-induced oxidative stress as well as $p$, Fas and caspase 12-mediated apoptosis. Amino acids 42: 1839-1855.

90. Das J, Ghosh J, Manna P, Sil PC (2010) Acetaminophen induced acute liver failure via oxidative stress and JNK activation: protective role of taurine by the suppression of cytochrome P450 2E1. Free Radic Res 44: 340-355.

91. Das J, Ghosh J, Manna P, Sil PC (2010) Protective role of taurine against arsenic-induced mitochondria-dependent hepatic apoptosis via the inhibition of PKC delta-JNK pathway. PLoS One 5: e12602.

92. Ghosh J, Das J, Manna P, Sil PC (2009) Taurine prevents arsenic-induced cardiac oxidative stress and apoptotic damage: role of NF-kappa B, p38 and JNK MAPK pathway. Toxicol Appl Pharmacol 240: 73-87.

93. Das J, Ghosh J, Manna P, Sil PC (2008) Taurine provides antioxidant defense against $\mathrm{NaF}$-induced cytotoxicity in murine hepatocytes. Pathophysiology 15 : $181-190$

94. Liu Y, Wu YM, Zhang PY (2015) Protective effects of curcumin and quercetin during benzo(a)pyrene induced lung carcinogenesis in mice. Eur Rev Med Pharmacol Sci 19: 1736-1743.

95. Hamza RZ, El-Shenawy NS, Ismail HA (2015) Protective effects of blackberry and quercetin on sodium fluoride-induced oxidative stress and histological changes in the hepatic, renal, testis and brain tissue of male rat. J Basic Clin Physiol Pharmacol 26: 237-251.

96. Parada E, Buendia I et al. (2015) Microglial HO-1 induction by curcumin provides antioxidant, antineuroinflammatory, and glioprotective effects. Mol Nutr Food Res 59: 1690-1700.

97. Rashid, K, Sil PC (2015) Curcumin ameliorates testicular damage in diabetic rats by suppressing cellular stress-mediated mitochondria and endoplasmic reticulum-dependent apoptotic death. Biochim Biophys Acta 1852: 70-82.

98. Rashid K, Sil PC (2015) Curcumin enhances recovery of pancreatic islets from cellular stress induced inflammation and apoptosis in diabetic rats. Toxicol App Pharmacol 282: 297-310

99. Ghosh, S, Bhattacharyya S, Rashid K, Parames CS (2015) Curcumin protects rat liver from streptozotocin-induced diabetic pathophysiology by counteracting reactive oxygen species and inhibiting the activation of p53 and MAPKs mediated stress response pathways. Toxicol Reports 2: 365-376.

100. Ghosh S, Banerjee S, Sil PC (2015) The beneficial role of curcumin on inflammation, diabetes and neurodegenerative disease: A recent update. Food Chem Toxicol 83: 111-124.

101. Sinha K, Sadhukhan P, Saha S, Pal PB, Sil PC2 (2015) Morin protects gastric mucosa from nonsteroidal anti-inflammatory drug, indomethacin induced inflammatory damage and apoptosis by modulating NF-KB pathway. Biochim Biophys Acta 1850: 769-783.

102. Bhattacharyya S, Ghosh S, Sil PC (2014) Amelioration of Aspirin induced oxidative impairment and apoptotic cell death by a njovel antioxidant protein molecule isolated from the herb Phyllanthus niruri. PLoS One 9: e89026.

103. Al-Gayyar MM, Al Youssef A, Sherif IO, Shams ME, Abbas A (2014) Protective effects of arjunolic acid against cardiac toxicity induced by oral sodium nitrite: effects on cytokine balance and apoptosis. Life Sci 111: 18-26.

104. Ghosh J, Das J, Manna P, Sil PC (2011) The protective role of arjunolic acid against doxorubicin induced intracellular ROS dependent JNK-p38 and p53mediated cardiac apoptosis. Biomaterials 32: 4857-4866.

105. Sinha M, Manna P, Sil PC (2007) Aqueous extract of the bark of Terminalia arjuna plays a protective role against sodium-fluoride-induced hepatic and renal oxidative stress. J Nat Med 61: 251-260.

106. Manna P, Sil PC (2012) Arjunolic acid: beneficial role in type 1 diabetes and its associated organ pathophysiology. Free Radic Res 46: 815-830.

107. Manna P, Das J, Ghosh J, Sil PC (2010) Contribution of type 1 diabetes to rat liver dysfunction and cellular damage via activation of NOS, PARP IkappaBalpha/NF-kappaB, MAPKs, and mitochondria-dependent pathways: Prophylactic role of arjunolic acid. Free Radic Biol Med 48: 1465-1484.

108. Manna P, Sil PC (2012) Impaired redox signaling and mitochondrial uncoupling contributes vascular inflammation and cardiac dysfunction in type 1 diabetes: Protective role of arjunolic acid. Biochimie 94: 786-797.

109. Pal S, Sarkar A, Pal PB, Sil PC (2015) Protective effect of arjunolic acid against atorvastatin induced hepatic and renal pathophysiology via MAPK mitochondria and ER dependent pathways. Biochimie 112: 20-34.

110. Chin D, Huebbe P, Frank J, Rimbach G, Pallauf K (2014) Curcumin may impair iron status when fed to mice for six months. Redox Biol 2: 563-569.

111. Kanai M (2014) Therapeutic applications of curcumin for patients with pancreatic cancer. World J Gastroenterol 20: 9384-9391.

112. Epelbaum R, Schaffer M, Vizel B, Badmaev V, Bar-Sela G (2010) Curcumin and gemcitabine in patients with advanced pancreatic cancer. Nutr Cancer 62: $1137-1141$

113. Saha S, Sadhukhan P, Sil PC (2014) Genistein: A Phytoestrogen with Multifaceted Therapeutic Properties. Mini Rev Med Chem

114. Jefferson WN, Padilla-Banks E, Newbold RR (2005) Adverse effects on female development and reproduction in CD-1 mice following neonatal exposure to the phytoestrogen genistein at environmentally relevant doses. Biol. Reprod 73: 798-806.

115. Jefferson WN, Padilla-Banks E, Newbold RR (2007) Disruption of the developing female reproductive system by phytoestrogens: genistein as an example. Mol Nutr Food Res 51: 832-844.

116. Kumar S, Baillie TA (2008) Minimizing metabolic activation in drug discovery. Handbook of Drug Metabolism: 597-618. 
Citation: Banerjee S, Ghosh J, Sil PC (2016) Drug Metabolism and Oxidative Stress: Cellular Mechanism and New Therapeutic Insights. Biochem Anal Biochem 5: 255. doi:10.4172/2161-1009.1000255

Page 11 of 11

117. Sangar MC, Bansal S, Avadhani NG (2010) Bimodal targeting of microsomal cytochrome P450s to mitochondria: implications in drug metabolism and toxicity. Expert Opin Drug Metab Toxicol 6: 1231-1251.

118. Guengerich FP (2008) Cytochrome p450 and chemical toxicology. Chem Res Toxicol 21: 70-83.

119. Lin JH, Lu AY (2001) Interindividual variability in inhibition and induction of cytochrome P450 enzymes. Annu Rev Pharmacol Toxicol 41: 535-567.

120. Guengerich FP1 (2006) Cytochrome P450s and other enzymes in drug metabolism and toxicity. AAPS J 8: E101-111.

121. Tang C, Lin JH, Lu AY (2005) Metabolism-based drug-drug interactions: what determines individual variability in cytochrome P450 induction? Drug Metab Dispos 33: 603-613

122. Ma Q, Lu AY (2011) Pharmacogenetics, pharmacogenomics, and individualized medicine. Pharmacol Rev 63: 437-459.
123. Meyer UA (2000) Pharmacogenetics and adverse drug reactions. Lancet 356 : 1667-1671.

124.Evans WE, McLeod HL (2003) Pharmacogenomics-drug disposition, drug targets, and side effects. N Engl J Med 348: 538-549.

125. Weinshilboum R (2003) Inheritance and drug response. N Engl J Med 348: 529-537.

126. Evans WE, Relling MV (2004) Moving towards individualized medicine with pharmacogenomics. Nature 429: 464-468.

127. Eichelbaum M, Ingelman-Sundberg M, Evans WE (2006) Pharmacogenomics and individualized drug therapy. Annu Rev Med 57: 119-137.

128. Lin JH (2007) Pharmacokinetic and pharmacodynamic variability: a daunting challenge in drug therapy. Curr Drug Metab 8: 109-136.

129. Topol EJ, Schork NJ (2011) Catapulting clopidogrel pharmacogenomics forward. Nat Med 17: 40-41. 